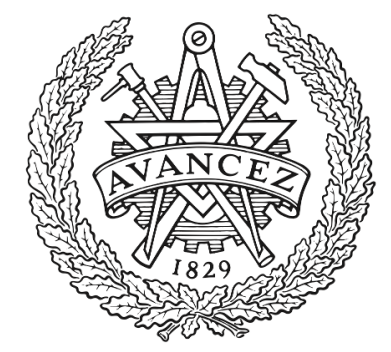

CHALMERS

UNIVERSITY OF TECHNOLOGY

\title{
Latent Groups in Online Communities: a Longitudinal Study in Wikipedia
}

Downloaded from: https://research.chalmers.se, 2023-04-26 15:01 UTC

Citation for the original published paper (version of record):

Lanamäki, A., Lindman, J. (2018). Latent Groups in Online Communities: a Longitudinal Study in Wikipedia. Computer Supported Cooperative Work, 27(1): 77-106.

http://dx.doi.org/10.1007/s10606-017-9295-8

N.B. When citing this work, cite the original published paper. 


\title{
Latent Groups in Online Communities: a Longitudinal Study in Wikipedia
}

\author{
Arto Lanamäki ${ }^{1}$ (1) \& Juho Lindman ${ }^{2}$ \\ ${ }^{1}$ Interact research unit, University of Oulu, PO Box 8000, Oulu, FI-90014, Finland (E-mail: \\ arto.lanamaki@oulu.fi); ${ }^{2}$ Applied Information Technology, University of Gothenburg / Chalmers, SE- \\ 41296 Gothenburg, Sweden (E-mail: juho.lindman@ait.gu.se)
}

\begin{abstract}
Research on online communities has shown that content production involves manifest groups and latent users. This paper conceptualizes a related but distinct phenomenon of latent groups. We ground this contribution in a longitudinal study on the Finnish Wikipedia (2007-2014). In the case of experts working on content within their area of expertise, individuals can constitute a group that maintains itself over time. In such a setting, it becomes viable to view the group as an acting unit instead of as individual nodes in a network. Such groups are able to sustain their activities even over periods of inactivity. Our theoretical contribution is the conceptualization of latent groups, which includes two conditions: 1) a group is capable of reforming after inactivity (i.e., dormant), and 2) a group is difficult to observe to an outsider (i.e., non-manifest).
\end{abstract}

Keywords: Online community, Wikipedia, Latency, Latent group, Longitudinal

\section{Introduction}

"latency: present and capable of emerging or developing but not now visible, obvious, active, or symptomatic"

\section{- Merriam-Webster Dictionary http://www.merriam-webster.com/dictionary/ latent}

In studies of online communities such as Wikipedia, much attention has been paid to the activity levels and types of users (Preece and Shneiderman 2009; Velasquez et al. 2014). Wikipedia article production allows different kinds of one-off, sporadic, and spot contributions (Ransbotham and Kane 2011) and also prolonged engagement (Morgan et al. 2013; Solomon and Wash 2014). It relies on pseudonymous identities rather than authenticated credentials; therefore, Wikipedia users' trust is based on the procedure rather than on the people (Jemielniak 2014). Conflicts are overcome through normative standards (Reagle 2010) and deliberative argumentation (Black et al. 2011; Hansen et al. 2009).

While Wikipedia is oriented toward anti-credentialism and self-organization (Benkler 2007), contributors do develop relationships between each other over the 
long term. These relationships bring advantages such as more efficient coordination of contributions, leading to faster production of high-quality content (Nemoto et al. 2011). Strengthened interpersonal relationships also increase mutual trust, enabling progression toward new roles and responsibilities within the community (Arazy et al. 2015).

In general, interpersonal relationships have a major impact on collaboration and creativity (Milgram 1967). Stanley Milgram introduced the classic small world theory, which attempts to measure whether humans are approximately within six degrees of separation to any other person. Building on Milgram's work, Uzzi and Spiro (2005) have demonstrated how innovation in Broadway musicals relies on dynamic configurations that derive from a social network of theater workforce. In contemporary digital settings, the small world phenomenon has been empirically studied in various online platforms such as Facebook (Daraghmi and Yuan 2014) and Twitter (Himelboim et al. 2017).

Conceptualizations of online relationships are often categorized under what Wellman and Rainie (2012) define as networked individualism, in which "people function more as connected individuals and less as embedded group members" (p. 12). Networked individualism focuses on "partial membership in multiple networks," rather than "permanent memberships in settled groups" (p. 12). Among these networked individualist approaches is social capital theory, which has provided useful insights to research on Wikipedia (Okoli and Oh 2007; Nemoto et al. 2011). In social capital theory, social relationships are seen as properties of individuals, of networks, or of both (Adler and Kwon 2002).

Despite the value of such individualist approaches, they may also represent a limitation by leaving potential blind spots for collective phenomena such as groups. One critique is that what qualifies as a tie in a network has tremendous implications for what kind of network becomes constructed (Grannis 2010). For Milgram, the network tie was defined by knowing the other on a first-name basis. Yet, other definitions are possible. Another critique would be that for collectives the identification is not between individuals, but of a shared "we" (Bannon and Schmidt 1989). Such strong togetherness is demonstrated, for instance, by the notion of a macroactor: a structure that appears more powerful and more sustainable than the sum of its individual components (Czarniawska 2017).

In "manifest" groups such identification takes place up front, allowing subsequent action to be performed collaboratively. In "emergent" or "latent" groups, initial collaboration occurs before group identification. Mutual action is what makes the group. Yet, research has thus far focused mostly on "manifest" groups.

We address this gap through the research question: How do recurring group collaborations occur over periods of inactivity? In this question "recurring group collaborations" imply that the group is a relatively consistent social structure and is to be viewed as an acting unit. "Over periods of inactivity" refers to the group's latent potential. To answer the question, we conducted an empirical research project in which we analyzed eight years of group activities (2007-2014) in Featured Articles 
(FA) collaborations in Finnish Wikipedia. Our study involved active Wikipedia contributors who were identified in our interviews as a part of an emergent group of Natural Science Enthusiasts (NSE).

This article adds to the literature by identifying and conceptualizing a new lens for computer-supported cooperative work in the context of Wikipedia. This kind of group work is easy to overlook unless the researcher is using in-depth longitudinal research approaches complemented with interviews and trace ethnography. Our lens helps to make this activity visible for researchers. Additionally, latency has rarely been studied using a group-level unit of analysis. As such, this paper adds to the multiplicity of study contexts of cooperative work in general and Wikipedia in particular.

The article is organized as follows. The next chapter offers a literature review on group work and latency. The third chapter presents the research context and the research methods. The fourth provides the longitudinal study of group collaborations. In Chapter Five, we reflect on these findings by contrasting findings with the existing research. Chapter Six discusses the implications of the findings and offers future avenues for research.

\section{Background and related work}

\begin{tabular}{lll}
\hline & Manifest & Latent \\
\hline Group & Section 2.2 & $\begin{array}{l}\text { Identified research gap } \\
\text { Individual }\end{array}$ \\
\hline
\end{tabular}

Our background is organized as follows. Section 2.1 discusses the literature on invisible participation in online communities, ranging from lurkers to latent users. Section 2.2 focuses on group work in online communities. Our argument is that, while online participation largely consists of sporadic individual contributions, many forms of group-level activities have been identified in previous literature. Most group studies, however, concentrate on "manifest" groups.

\subsection{From lurkers to latent users}

Our central argument in this paper depends on Velasquez et al. (2014), who identified the participation potential of inactive veteran contributors in the notion of "latent users." We see this notion to represent the third wave of theorizing of online participation. ${ }^{1}$

\footnotetext{
${ }^{1}$ We use the term "wave" to imply a chronological order of theoretical developments, not normative preferences. All three waves are overlapping, and none of the newer ones have displaced previous ones. These three waves are used here for illustrative purposes to present the differences in online participation literature and how our own view differs from these. Instead of the term "wave," we also considered other terms such as "perspective," "paradigm," "approach," and "stance," but found "wave" to be the most appropriate.
} 
What is the third wave of online participation theorizing? We see that the first wave represents a dualistic view consisting of active participation and nonparticipation (Dennen 2008). The interest in studying this dualism has risen from the general observation that in almost all online communities, most users do not contribute, but the majority of them are "lurkers" who read and observe the content. Nielsen (2006) was an early advocate for the rule of thumb that lurkers constitute the silent $90 \%$ majority of any online community. Empirically, it has been found that readers constitute more than $99.9 \%$ of all Wikipedia users (Halfaker et al. 2013b). And according to Priedhorsky et al. (2007), a diminutive proportion of Wikipedia contributors have written those pages that gain the majority of readership.

The term "lurker" has always had negative connotations, implying unproductive "free-rider" behavior (Cranefield et al. 2015; Smith and Kollock 1999). A common aim for first-wave research is to find mechanisms for "de-lurking" (e.g. Rafaeli et al. 2004): how to turn a user from the dark side of inactivity to the bright side of activity. Sun et al. (2014) conducted a literature review on lurking studies, in which they identified four reasons for lurking: environmental influence, personal preference, individual-group relationship, and security considerations.

The second wave takes a more nuanced characterization, emphasizing a sequential progress toward active participation. Malinen (2015) harvested research on lurking and concluded, "a central theme in research on participation that seems to divide opinions is whether lurking is participatory activity or not" (p. 232). This is a central difference between the first and the second wave. The first paints lurking as nonparticipation, while the second sees lurking within the continuum of participation. For example, reading has been identified as a gateway activity that increases a person's understanding of the norms and processes of a community (Antin and Cheshire 2010). Dejean and Jullien (2015) found that the best predictors for future participation of lurkers are not in the transition from the periphery to the core. Instead, the two most important aspects are the time between the discovery of the community and the first contribution, and the effort put into the first contribution. An implication of this is that the longer users remain non-contributors and the smaller their first-time contribution effort is, the more improbable it becomes that they will ever become regular contributors. In addition, Kane and Ransbotham (2016) identified how consumption and contribution positively reinforce each other, but during content improvement, it becomes less probable that newer consumers will convert to contributors.

As previously argued, the identification of a "latent user" by Velasquez et al. (2014) signals a third wave in participation theorizing. Unlike the first wave, the third is not dualistic. Unlike the second, the third does not involve a unidirectional sequence from non-participation to participation. The third can involve shifting positions in the space between non-participation and participation, including a backward path. The notion of a "latent user" implies the future contribution potential of presently inactive veteran members. They argued that " $[\mathrm{u}]$ nlike 'lurkers', latent users know, and may be expert in, the norms and mechanisms of the community, but 
are currently not actively contributing content” (p. 22). 'Latent user' is an interesting conceptualization because it is non-dualistic between a community insider and an outsider.

Velasquez et al. (2014) characterize latent users as those who "have contributed to a level where they have learned the process and norms around adding their own content, but who have changed their behavior and no longer contribute content in the same fashion" (p. 31). A latent user is not just any inactive user, but someone who "would regularly read content on the website and would occasionally talk with other users on the site, but felt like they did not have anything (yet) valuable enough to contribute" (p. 31). Latency differs from inactivity in that there is the possibility, or an inherent capability, of emerging or developing to a previous state of action.

Velasquez et al. (2014)'s formulation of a "latent user" is, as the name suggests, is on the level of an individual. Yet, it is worth pondering whether latency can also occur as a collective phenomenon. After all, the Merriam-Webster dictionary definition of latency as something that is "present and capable of emerging or developing but not now visible, obvious, active, or symptomatic" does not limit this phenomenon to any single level of analysis.

On a collective level, latency would imply that "something" is present but not visible or obvious to the individuals who are not part of the collective. Our view is that under certain conditions, collective-level phenomena arise from actions between individuals. Recurring collaborations provide people with a sense of belonging, and they start to see the benefits of acting as a social unit instead of as an individual. Importantly, the collective phenomena are experienced by those involved in the action. Consequently, people outside the collective may not even be aware of its existence.

\subsection{From sporadic contributions to group work}

Individual users from different parts of the world partake in many-to-many collaborations to produce complex artifacts such as encyclopedias (Kudaravalli and Faraj 2008; Zammuto et al. 2007). The collaborations often take place in short-term ad-hoc engagements featuring a high rate of membership turnover (Ransbotham and Kane 2011; Halfaker et al. 2013a). Turnover means both departures and additions to community membership (Jiang and Wagner 2015). In practice, many users are only periodically active, making it hard to specify who is in and who is out. A combination of both short-term and long-term tenure participants has been shown to be an effective mix in article production (Ransbotham and Kane 2011).

In this article, we are interested in persistent forms of participation, of which there are many types. In Wikipedia and other open collaboration platforms, governance is supported by "persistent but malleable social structures" (Forte and Lampe 2013). Such social structures are not restricted to governance, but may also exist for content production. Coordinated project work takes place on dedicated project pages, called Wikiprojects (Morgan et al. 2014; 2013). These are wiki pages dedicated to a 
particular theme, with an aim to attract potential contributors to work together in a coordinated manner. To generalize, Wikiprojects are manifest groups, meaning groups that are explicitly identifiable on the platform to enable collaborative work.

In this article, we concentrate on latent group collaboration. We specifically orient ourselves with respect to the group dynamics literature, which approaches groups as emergent states (Waller et al. 2016). An emergent state refers to higher-level phenomena rising from - while being more than - their individual components. In other words, this implies that group-level "features have not been previously observed in lower-level phenomena from which they emerge, and that they cannot be perfectly reduced back to their lower-level constituent parts" (Waller et al. 2016). Such collective agency bears similarities to the notion of the macro-actor in actornetwork theory (Czarniawska 2017).

Figure 1 depicts this recent critical review on dynamism on group/team dynamics.

Emergent groups originate from interactions between people (Waller et al. 2016). After such interactions recur, the group emerges as its own entity. In such an emergent state, the group has different levels, meaning that the group arises from its interactions. The state emerges from lower-level components ("supervenience") but is not reducible to them. Once a group has emerged, it may endure coherently

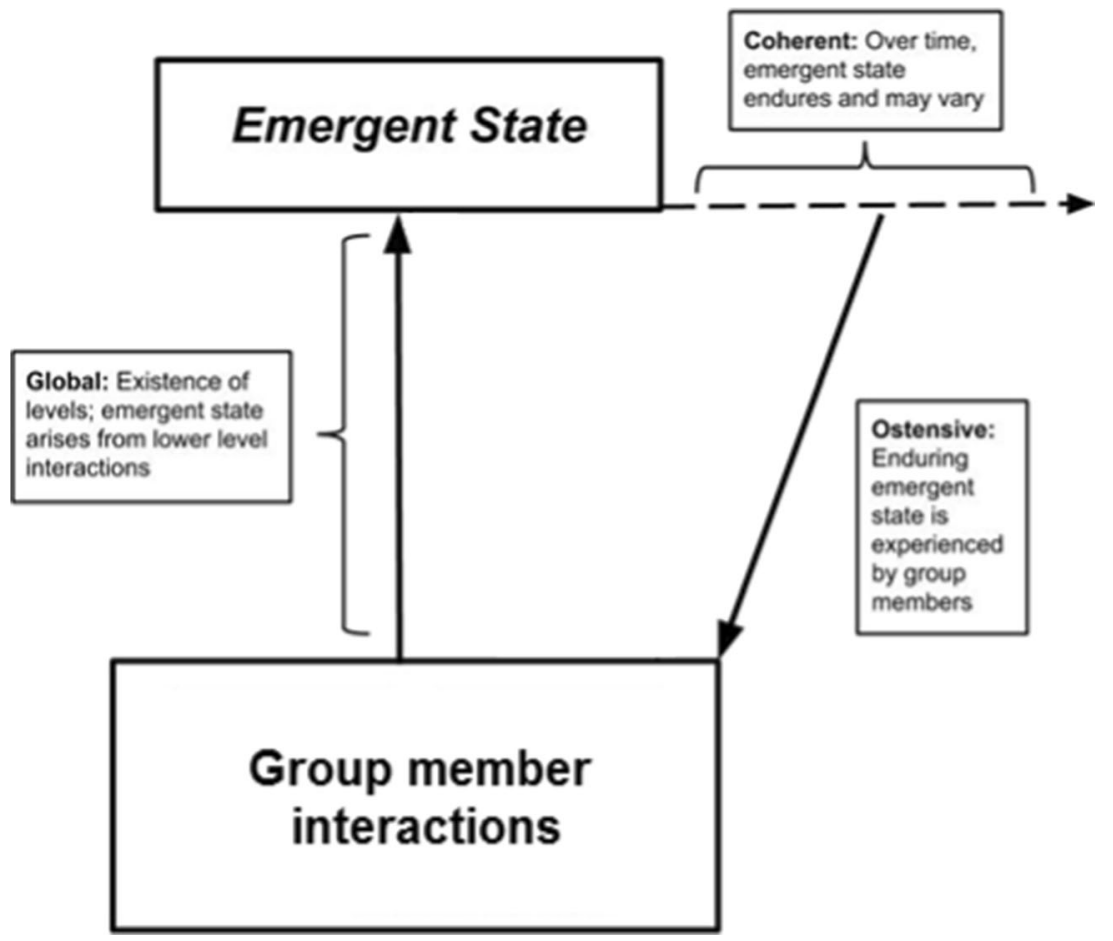

Figure 1. A model of group dynamism, conceptualizing the emergent state (adapted from Waller et al. (2016)). 
over time. The group is ostensive, meaning that members are able to perceive and sense the emergent wholes.

Once a group has emerged, the question becomes how-and how long-it endures. Waller et al. (2016) argued that groups may emerge and then endure, and while they endure, their activities may vary. Coherence does not mean permanence; it can mean both endurance of the emerged state as well as endurance and variability. Variability means that the states emerge and change when evolving over time as opposed to other similar concepts (such as structure). For a full account of nuances of the earlier literature, see Waller et al. (2016).

We strongly agree with Waller et al. (2016) that such phenomena require longitudinal research that complements earlier studies in laboratory settings and/or on student population (Curşeu and Schruijer 2010; Mathieu et al. 2005; Okhuysen and Richardson 2007).

As a summary, we have on the one hand identified research on readership and lurking, which for our purposes culminates in the notion of "latent user" Velasquez et al. (2014). On the other hand, we have identified research on "manifest" group work (Solomon and Wash 2014; Morgan et al. 2013), as well as other studies that hint at emergent collaboration (Arazy et al. 2017; Keegan 2015; Keegan et al. 2012). We argue that a research gap exists in the cross-section of these two bodies of literature. The extant literature has not yet included studies of latent group work, which is what we aim to do in this paper.

In the next section, we discuss our research context and methods.

\section{Research context and methods}

Our research takes a qualitative research approach involving two methodological choices: interviews and trace ethnography. We have analyzed the collected data and contrasted them to the extant literature. This, in turn, has led to more data collection, more analysis, and more reflection and comparison. In other words, the process has been iterative.

After conducting interviews, we did a process of trace ethnography, following the guidelines of Geiger and Ribes (2011). They present two basic principles of trace ethnography. First, "documentary traces abound in today's technological systems" (p. 1). Second, "documentary traces are the primary mechanism in which users themselves know their distributed communities and act within them" (p. 1). This calls for an immersion in the situated actions, "an ethnographic understanding of the activities, people, systems, and technologies which contribute to their production" (p. 1).

We have investigated people, content, and mediating technologies. However, we emphasize that the unifying concept is practice. Placing practice as the unit of analysis fits well with the spirit of trace ethnography (Geiger and Ribes 2011). It is also an established unit in several research approaches (Jarzabkowski 2004; Kuutti and Bannon 2014; Nicolini 2013). 
In the following sections, we describe our research context, data collection, and analysis. The separation of collection and analysis is mainly conceptual, as we have iteratively progressed between collection and analysis of data.

\subsection{Research context: how wikipedia editors create featured articles?}

Wikipedia has served as a context for a plethora of previous studies on online communities and collaboration (Mesgari et al. 2015). In this article, we focus on the Featured Articles (FA) and their production among one group. FAs represent the highest quality of Wikipedia content and have been of great interest to researchers (Jones 2008; Kane et al. 2014; Stein and Hess 2007). In English Wikipedia, about 4400 articles - or $0.1 \%$ - are featured.

Most scholarly research is done on English Wikipedia, but some studies exist on German Wikipedia (Stein and Hess 2007), Chinese Wikipedia (Liao 2009), or a combination of several language editions (Stvilia et al. 2009). This has implications for the study of the FA process because each language community is autonomous in deciding quality standards and related processes. For example, German Wikipedia has two types of featured articles: excellent and worth reading (Stein and Hess 2007).

Our research context is the Finnish edition of Wikipedia. It was started in 2002 but gained momentum only in 2004. It is the 22nd-largest Wikipedia edition and has 402,000 articles (November 2016). It is also, notably, the only encyclopedia now updated in Finnish. In Finnish Wikipedia, there are three quality levels of articles: "Promising Article," "Good Article," and "Featured Article," literally "Recommended Article." Practically, the FA articles in English and Finnish Wikipedia are similar, even though they are named differently. The English label "Featured" refers to "being featured on the front page," while the Finnish "Recommended" implies that people recommend others to read the highest quality content. The Featured Article process, like the Good Article process, lasts for two weeks in the Finnish Wikipedia. This is similar in the English language edition.

\subsection{Data collection and analysis}

To answer our research question, we used a qualitative and interpretive research process to investigate particular Wikipedia collaborators' work in the longer term. We gathered data using a variety of sources and analyzed it, as described in Appendix Table 4. We translated all interviews and other source materials from Finnish to English.

The interview process started in 2009. We started by identifying prolific Wikipedians in Finland, using a ranking list of users who had contributed the most edits. We assumed that the users with the highest number of edits had the most indepth knowledge about Wikipedia and were thus most able to identify and reflect on issues. We approached 51 of them in November and December of 2009. Twentyeight did not reply. Eight answered but declined to participate, and 16 accepted the 
request. Interviews with 3 of those could not be arranged because of scheduling conflicts. Eventually, 13 interviews were conducted in early 2010.

The interviews were semi-structured and evolved openly into emerging themes respondents provided. The interviews yielded insights about their communication patterns. Importantly, the idea of "latent groups" was not part of the interview guide, but it emerged through the narratives our respondents told us. Thus, the group and its activities were identified during research conduction. The research process can be described as iterative, based on abductive inquiry (Martela 2015). It was largely influenced by discoveries made during the process (Locke 2011).

The original interviews were conducted individually face-to-face in various locations in Finland. They lasted from $1.5 \mathrm{~h}$ to $3 \mathrm{~h}$ each. Every interview had the same protocol. We tape-recorded and transcribed each. After each transcription, we wrote a short summary containing information that was not included in the transcription: how the transcriber had experienced the interview process and the general perception about the content and validity of the interview. Four people were involved in the transcription part of the interview process. In total, these transcriptions consist of about 300 pages of text.

After these interviews, we then proceeded to the trace ethnography part of the study, in which we followed the guidelines of Geiger and Ribes (2011). Using the descriptions we had heard from the interviews, we explored collaborative practices in Wikipedia. This included tracing of performances on various kinds of pages on Wikipedia, including article pages, article talk pages, user talk pages, discussion forums, and Wikiproject pages. ${ }^{2}$ We also applied various Wikipedia analytics tools in tracing these interactions, especially the tools "Contributors," "Wikipedia Page History Statistics," and "X!'s edit counter" (which morphed into "X!'s tools" during the research process). ${ }^{4}$

In early 2014, we decided to conduct a new set of interviews with the investigated group. During the preparations for a new interview round, it appeared that one of the earlier respondents had quit his Wikipedia participation. Another respondent suggested that instead of individual interviews, we should organize a group interview over Skype.

A subsequent interview took place in early February 2014. This was conducted with two NSE members, who were interviewed together. Our purpose for this interview was first to let respondents evaluate and reflect on the previous findings and theorizing. This could potentially increase the relevance of those findings (Bygstad and Munkvold 2011). Second, we wanted to gather more information

\footnotetext{
${ }^{2}$ See Broughton (2008) for a detailed description of the many types of pages in Wikipedia and their purpose in various communicative practices.

${ }^{3}$ This has ceased working. The URL was https://toolserver.org/ daniel/WikiSense/Contributors.php. The URL currently redirects to X!'s tools https://tools.wmflabs.org/xtools-articleinfo/index.php (Accessed November 15, 2016)

${ }^{4}$ These are available at https://en.wikipedia.org/wiki/Wikipedia:Tools
} 
about how their Wikipedia activities had changed from the previous interviews that were conducted four years ago. Third, we wanted to discuss various Wikipediarelated topics that had research potential.

After this second round of interviews, we further explored Wikipedia collaborations using trace ethnography, as explained earlier. We highlighted all the instances when the respondents discussed their group. Of special interest were those when the respondents discussed the group and its activities. We analyzed the highlighted parts in further detail as material for further analysis, and the resulting story of the group is below.

Finally, we corresponded with the key respondents by email. In these emails, we asked for information on details we noticed when revisiting the interview data and examining the Wikipedia interactions though trace ethnography. This combined all the previous means of data collection, thus contributing to triangulation of the qualitative data (Myers 2013).

\subsection{Our respondents, the natural science enthusiasts}

Our key respondents were initially just informants, but during the process, they also became the study subjects. They provided the clues that helped us to identify group activities in Wikipedia. The group does not manifest on dedicated teamwork pages like Wikiprojects (Morgan et al. 2013; Solomon and Wash 2014). Our key respondents perform group activities as topic experts within natural sciences who are concerned with the production of Featured Articles. Outside of group-based activities, the members perform individual tasks and sporadic collaborations. Some of them have been inactive at times. It would have been difficult to identify this group from Wikipedia itself had we not conducted the interviews. Our study concerns this group, the Natural Science Enthusiasts (NSE; Table 1).

Many NSE members have met each other face-to-face. The first meeting was in 2009, when one interviewee decided to host a meeting where four members were present. As Albval recalled, "We organized a meeting with people who are interested in biology-related topics. We met, chatted, drank some red wine and that's it." As Tappinen described it in 2010, "This particular event has been the only face-to-face

Table 1. Natural Science Enthusiasts (NSE), with key respondents italicized (28. October 2014).

\begin{tabular}{lllll}
\hline Pseudonym & First edit & Most recent edit & Total edits & Pages created \\
\hline Tappinen & 16.4 .2005 & 27.10 .2014 & 72,850 & 12,181 \\
albval & 31.8 .2006 & 16.4 .2014 & 36,722 & 2504 \\
MiPe & 19.2 .2006 & 28.10 .2014 & 81,914 & 10,240 \\
QWerk & 11.2 .2007 & 11.4 .2011 & 21,290 & 1672 \\
PtG & 17.6 .2005 & 28.10 .2014 & 71,389 & 5265 \\
Tanár & 5.9 .2007 & 27.10 .2014 & 22,894 & 1106 \\
Uvainio & 31.8 .2006 & 14.10 .2014 & 4656 & 561 \\
Tikkakit & 10.11 .2006 & 14.2 .2010 & 4244 & 1951 \\
\hline
\end{tabular}


meeting I've participated in so far. But we've agreed that this event will be held again next year, so yes, this will be a recurring [...]. Actually it was funny that in this meeting I met one person whom I've collaborated with a lot in Wikipedia. When we met in person, he said he had thought I was an older man! He realized that I'm a woman only when we met face to face! [...] (Laughter)."

The fact that the two close collaborators did not know each other's gender is evidence that not many personal themes came up during the collaboration process. While participants are deeply involved in collaboration in Finnish Wikipedia, it is directed by content-production goals and is not often necessarily "social" otherwise.

Table 2, summarizing the collaborative projects of NSE members, indicates the amount and types of effort each contributor has made to each collaborative project. However, just looking at the edit count will give a false picture of the collaborative dynamics. An edit means a push of the "save" button in the edit window of the wiki and does not indicate how big a change one edit is. Albval noted, "I'd like to make one observation [about this table]. Tappinen does not seem to have any edits in the Kurjenrahka article. However, she did a big effort in that project by 'blue-fying ${ }^{6}$ a majority of its hyperlinks (for example, Vaskijärvi national park, most of the 'bugs'...)" (October 28, 2014).

\section{Findings}

In this section, we present the inner workings of the NSE group in Finnish Wikipedia. The NSE group has collaborated on a number of projects over the years (Table 2). For our analysis, we selected three projects through which to gain insights on the group's activities. These three selected projects represent their first project ("Whooper Swan," 2007), the latest project ("Lily of the Valley," 2013-2014), and one project in between ("Porcini," 2009).

In what follows, we describe these three projects. For each of the three, we first describe the trajectory from the birth of the project until the achievement of the goal (Featured Article status). Then we analyze how the group transitioned to a new project after a period of inactivity.

\subsection{The "Whooper Swan" article (2007)}

Already before the fall of 2007, some Finnish Wikipedia users were writing enthusiastically about natural science topics. For example, of the future-NSE collaborators, user Tappinen did her first edit in April 2005, MiPe in February 2006, and albval in

\footnotetext{
${ }^{5}$ The original Finnish word is sinistää, a verb made up from the noun sininen (blue). This refers to the act of turning a link from red to blue by creating the page it links to.
} 
Table 2. NSE article projects.

\begin{tabular}{|c|c|}
\hline Projects & Members involved (amount of edits) \\
\hline Whooper Swan (2007) & $\begin{array}{l}\text { Tappinen (84), albval (35), Tanár (23), Tikkakit (19), PtG (15), } \\
\text { MiPe (12) }\end{array}$ \\
\hline Meningomyeloseele (2008) & Uvainio (132), albval (102), Tappinen (10), QWerk (3) \\
\hline Snow (2009) & Tappinen (82), Tanár (34), albval \\
\hline Porcini (2009) & albval (120), Tappinen (38), MiPe (3), Tanár (3), PtG (1) \\
\hline Puffer Fish (2009) & Tappinen (51), albval (16), MiPe (6), PtG (4), Tanár (1), QWerk (1) \\
\hline Sulphuric acid (2009) & MiPe (96), uvainio (31), Tappinen (16), QWerk (15) \\
\hline Mosambik (2009) & Tappinen (141), PtG (24), MiPe (2) \\
\hline Vietnam (2010) & (128), MiPe (4), PtG (3), albval (2), Ta \\
\hline $\begin{array}{l}\text { Kurjenrahka National } \\
\text { Park (2010) }\end{array}$ & albval (252), Tanár (18), MiPe (1), Tappinen (1) \\
\hline Lily of the Valley (2013-14) & albval (118), Tappinen (23), MiPe (20), PtG (9), QWerk (2) \\
\hline
\end{tabular}

August 2006. The work of these users was individual-based, with accidental shortterm collaborations occurring here and there.

The origins of the NSE date back to the Featured Article process of the "Whooper Swan" (Laulujoutsen, Cygnus Cygnus) article in 2007. This collaboration laid the foundations for many future NSE projects. The "Whooper Swan" article in Finnish Wikipedia was initiated in early March 2004. For the first several years, from its first edit until the end of 2007, this Wikipedia article did not show any particular dedication from any users. Only a handful of edits were made, and no discussion occurred on the article talk page.

But then something happened. On October 20,2007, a user with the pseudonym Tikkakit asked a provocative question on a Finnish Wikipedia discussion forum for miscellaneous topics: Is Finnish Wikipedia a voice of The Vatican? The user had carefully examined the list of Featured Articles. He had counted that 15 (12.6\%) out of the total of 119 Featured Articles concerned the Catholic Church: popes, the Vatican, and St. Peter's Basilica. Tikkakit argued that at minimum this represents a topical bias, if not some kind of a conspiracy.

Quickly, other users joined the conversation. They explained that the "bias" is just a result of some contributors' enthusiasm about such topics. Instead of targeting against this set of articles, users should provide high-quality contributions for a broader variety of topics. The very next day user Tappinen came up with a practical challenge for Tikkakit. At the time, Finnish Wikipedia had only one Featured Article about birds. Tappinen gave three concrete suggestions of articles with collaborative potential: "Could it be Whooper Swan, Greenish Warbler, or Spotted Crake," she asked.

Tikkakit quickly answered that he thought Tappinen's offer was interesting. Tikkakit picked Whooper Swan because it is the national bird of Finland. The two were joined by many other contributors. Already during the remaining eleven days of 
October 2007, eight different users edited the article 55 times. Just one was anonymous, and none were bots. Tappinen (33 edits) and Tikkakit (14 edits) were the two most active contributors. In addition, the article Talk page became active. Tappinen and Tikkakit were having a dialogue to coordinate the tasks and the direction of the article. On October 25th the two started weighing on the possibility to initiate the peer review, which is a mandatory process on the way toward the Featured Article status.

The peer review took place from October 28th to November 15 th. This period saw an increase in the editing activity in the article and the addition of new contributors. The peer review page was commented on by 11 different users with evaluative and constructive comments. Right after the peer review period had ended, Tappinen moved the Whooper Swan in the Featured Article nomination process. This process lasted from November 15 th to November 30 th. The nomination process provided 26 votes for and 1 against the nomination, a strong 96\% support. During the process, users gave very positive feedback. For example, user Tosalmi stated that he had "followed how this article had developed, and had nothing to add to it." Username ukas said that he had "read it twice because it is that good."

All in all, participants considered the project a great success. It was a success in terms of its result, as it provided the second bird-themed Featured Article in Finnish Wikipedia. It was also a success in its collaborative process. Before the "Whooper Swan" collaboration, there was no NSE. After the collaboration, the collaborators had created not just a Featured Article, but a sense of belonging. This was confirmed in our interviews. Several of our informants identified the "Whooper Swan" as the process during which the NSE emerged as a group. This project provided a template of action for several subsequent projects.

\subsection{The "Porcini" article (2009)}

After the group of Natural Science Enthusiasts had emerged during the foundational Whooper Swan project, the group continued collaborating in two to-be Featured Articles: "Meningomyeloseele" in June 2008 and "Lumi" (Snow) in FebruaryMarch 2009. The "Meningomyeloseele" article included the contributions of a then-new NSE collaborator Uvainio (132 edits). Other NSE contributors on the "Meningomyeloseele" article included albval (102), Tappinen (10), and QWerk (3). The "Lumi" article included contributions from Tappinen (82), Tanár (34), albval (19), PtG (5), and MiPe (1). During these second and third projects, the lineup of NSE became rather stable. Tappinen recalls these events:

“I can’t remember when Tanár joined. We four (albval, Tanár, uvainio and Tappinen) really made an effort in the Peer Review process and Featured Article process [in the 'Snow' article]. MiPe had his matriculation examination and entrance exams at that time. That was in 2009." - Tappinen, on February 10, 2014 [source: email correspondence] 
We now elaborate on the process of the fourth NSE project, "Porcini" (herkkutatti, boletus edulis). The article was first created in March 2005, but until March 2009 it attracted very few edits. On March 29th came an enormous burst of editing activity. On March 31, 2009, Tappinen started a new thread on the Wikiproject:Mushrooms project page, titled "A campaign for quality improvement?" She reported that the status of mushroom articles was weak: no Good or Featured articles covered the topic. She noted that "Porcini "and "Chanterelle" were among the most regularly read articles in Finnish Wikipedia, according to the August 2008 statistics. She said that she had started to improve the "Porcini" article and invited others to join in. In addition, she asked whether other Wikipedians were aware of mushroom articles "that have the potential for a greater storyline." Additionally, she noted that the "gyromitra esculenta" article was Featured in the English Wikipedia, and "Porcini" was labelled Good in Polish Wikipedia, implying that these two could be used as role models.

After midnight on April 1, 2009, Tappinen wrote a new message on albval's user talk page. The message was titled in the South-Western Finnish dialect "Tatei" (the official Finnish would be "Tatteja"), which refers to the Boletaceae family of mushrooms. She told albval that she had been working on the "Porcini" article and had set some challenges on the article talk page. Albval then answered that he would continue on the article talk page.

One minute before midnight on April 31, 2009, Tappinen wrote on the "Porcini" article talk page that her sources contained nothing about what types of larvae or parasites are associated with porcini mushrooms. Tappinen also pondered how information should be divided between the "Boletaceae" family article and the "Porcini" article. Eighteen minutes later, albval replied that he had just written the article for the Pegomya hyoscyami larva (which had already been hyperlinked on the "Porcini" article), but also stated that this larva was not mentioned in his mushroom book within the porcini entry. This led to a longer discussion of whether one unclearly stated source had assigned pegomy hyoscyami as a parasite of this particular mushroom or whether some of the Anthomyiidae family of flies are parasites to some of the Boletaceae family of mushrooms. Albval had started to work on a related article on Mycetophilidae, which was identified as the porcini larvae.

This initial sprint of contributions in the article lasted until April 4th. On April 20th, albval asked what should happen next: "Shall we put this to peer review and try to achieve a Good/Featured Article status, or should we just move on to [working with] the next mushroom? I'm fine with either way, but I think we already could achieve Good Article with this. What do you others think?"

Soon afterward, the article was put into the peer review process for one month. A total of nine users participated in the process: albval, Tappinen, PtG, Tanár, and five others. During the peer review process, the article structure was improved, referencing was clarified, the introduction was extended, use of photographs was debated, and etymological details were fixed. Albval actively coordinated the 
process, and Tappinen was the second most active editor. Tanár contributed by improving terminological consistency with the Russian and Basque Wikipedias.

During the peer review period, Tappinen noted on albval's user page that she had applied Google Translate to the Polish version of the page. This revealed some aspects that Finnish sources did not contain, such as that the biggest porcini weighed $5 \mathrm{~kg}$ and that the species had been endangered previously.

After the article completed peer review, it was edited just twice in May 2009. During May, albval and Tappinen had a conversation about the status potential of the article. Albval was convinced that the article would get the Good Article status but was unsure about how the Featured Article process would go. Then in June, the article was again under intense improvement, when the article was put into the Good Article nomination process (June 7th until June 14th). The voting process was straightforward: the article received $100 \%$ support for nomination from a total of 21 voters.

In July 2009, the article was brought to the Featured Article nomination process by albval. He introduced the article in the following way: "All available source material has been exhausted [and it does not bring new insights to the article]. This article that I and Tappinen have been working on is now on the Featured level. The culinary aspects are in a large role, but it's understandable because this is an edible mushroom with a long tradition. The source material (i.e. mushroom books) emphasize the food perspective. However, I've gone through the Web of Science scholarly database, and I've tried to improve all other parts of the article as well. Please take a look at the archived Peer Review and the Good Article nomination processes."

The Featured article process brought some discussion on the article length and emphasis. Users who criticized the article wished that the article were longer and did not have as much focus on porcini's culinary uses. One reason for this criticism was that a Wikipedia policy states that "Wikipedia is not a food recipe or a cookbook." However, the critics were not able to point out which particular aspects should be improved or how to add length. Tappinen also noted that "sources on edible mushrooms tend to emphasize culinary aspects, while poisonous mushrooms tend to focus on poisons. There is not much to be told about mushrooms that are neither edible nor poisonous." After the FA process was over, the voting results were again very clear: $100 \%$ support from a total of 21 voters.

Since October 2009, the Porcini article has not been edited much. The most active contributor (a bot) has edited it three times in about five years. In other words, the article has largely retained its form since it received FA status.

Respondents considered the Porcini collaboration to be continuing the group work efforts that had started with the "Whooper Swan" article. Compared with the first project, the Porcini collaboration introduced more equal participation among the group members. Member Albval stated that "Porcini was a more balanced joint operation [than Whooper Swan was]." - Albval, on February 18, 2014 [source: email correspondence]. 


\subsection{The "Lily of the Valley" article (2013-14)}

In the early February 2014 interview with Tappinen and MiPe, "Lily of the Valley" was identified as the most recent NSE project. "Possibly we'll be able to push that into a Featured Article at some point." (MiPe, 4.2.2014).

Already toward the end of the active stage of the development of "Whooper Swan," there was a moment when on November 17, 2007, Tappinen wrote on Tikkakit's Wikipedia user talk page and thanked Tikkakit for his contributions. Tappinen proposed further collaboration around some other article. Could it this time be "Norway Spruce (Picea abies)," "Saimaa Ringed Seal," or "Lily of the Valley"? Tikkakit said that he was also happy with this "Whooper Swan" collaboration. He thought that "Lily of the Valley" might be a good choice because it is the national flower of Finland. Tappinen answered that the "Lily of the Valley" article would probably never achieve Featured Article status. She thought those users who assess nominees for such status by article length would never be satisfied. Instead, Tappinen saw more "FA-potential" in the spruce article. Thus, the collaboration did not start then.

Between 2007 and 2013 there was hardly any activity on the article. Then on April 25, 2013, a sudden change occurred: NSE (Tappinen, albval, and MiPe) started to work on it. Tappinen describes the origins for the active production phase of this article: "This ['Lily of the Valley'] project started when I was on a sick leave and I was really bored. I sent a message to albval: 'I'm bored, let's work on some article.' Albval replied me 'yes, let's fix 'Lily of the Valley."' So we worked on that together for a while. This flower is horribly poisonous, so we also needed someone who could write about the chemistry aspect. We needed someone who knew chemistry, so we sent a message to MiPe and asked him to contribute to this project. Afterward, we sent a message to Tanár that we need language help." - Tappinen, on February 4, 2014 [source: interview].

During the two weeks until May 8th, the article improved significantly. Toward the end of this two-week sprint, the NSE members brought the article into the Good Article process. The article gained "Good" status with $100 \%$ support from a total of 9 voters. The process was very straightforward, with no critique coming from anyone. This process ended on May 13, 2013.

After the article received Good Article status, its development stagnated for several months. Albval re-activated and contributed 18 edits in two days starting on November 6th and initiated the Peer Review process on December 3th, 2013. During the Peer Review, discussion on the article talk page was also relatively active. The article introduction was evaluated as "weak," and users requested better description of the visual characteristic of the flower. MiPe stated that he had improved content on the poisons, "as requested by albval." Users Velma and Tanár indicated that once this article was brought into the Featured Article process, they would support the nomination.

In the case of "Lily of the Valley," the Peer Review process ended on February 12, 2014. A week later, the article was taken into the Featured Article process. The article 
received the FA label on March 6, 2014, with 100\% support from 15 voters. There was mild criticism during the process: "We asked Tanár to proofread when someone at the [Featured Article process] reviews stated that "the language [in the article] is horrible." Tanar replied that he "could take a look next week" and then people started to ask Tanar to proofread even before taking the articles to peer-review. [...] I have done quite a few articles on nation states and in the reviews, it's always the same people who say something about sports, economy, geology etc. So you know when you write the next one who to ask to have a look before taking it into the peer-review. For example, in this peer-review, it is Tanar who mentions the language [...]" Tappinen, on October 17, 2014 [source: email correspondence].

An important detail here is that albval had not contributed at all since May 2012. In other words, he had become a latent user. He became active again in April 2013 for a couple of months. Afterward, he was completely inactive again between June and October 2013 and revitalized again in November 2013. In his later activity periods, albval concentrated fully on the NSE collaboration.

The agreement between NSE collaborators ensured a mutual commitment to this particular article. As they had worked together for several years, they knew each other's strengths. For example, when Tappinen and albval identified a need for chemistry expertise and language editing, they could turn to MiPe and Tanár, respectively.

\section{Discussion}

We contribute to the research literature by theorizing latent group is a new lens to view group work in online communities. Our work is grounded in a detailed analysis in Finnish Wikipedia. The group that we have labeled NSE first emerged in Finnish Wikipedia in 2007 in an FA project concerning the "Whooper Swan" article. Afterward, the group has contributed several Featured Article projects in natural science topics and sustained its activities over periods of inactivity. We have analyzed three projects in this paper, yet the group has collaborated on many other projects as well (Table 2).

Table 3 below describes the group latency by taking three slices of time (2007, 2009 , and 2013/14) in the different projects of our data. This table describes how the latent group was formed and lived on through several different projects.

In this discussion, we describe the "two sides of the coin" for latent groups. The first meaning of latency is a more traditional definition, that when something is latent it is inactive (5.1). The second meaning refers to the periods when the latent group is active (5.2). Even in this active period, the group is not visible or obvious as a group to outsiders. We elaborate on these aspects in the following sections.

\subsection{Latency during inactivity}

We have conceptualized latency as a group-level phenomenon, while extant research has treated it on an individual user level. Velasquez et al. (2014) treated latency as 
Table 3. Group latency in the three projects we examined.

\begin{tabular}{ll}
\hline $\begin{array}{l}\text { Project } \\
\text { and year }\end{array}$ & Latency During Inactivity \\
\hline $\begin{array}{l}\text { Whooper } \\
\text { (in between) }\end{array}$ & $\begin{array}{l}\text { The participants have a shared } \\
\text { understanding of skills and interests. } \\
\text { The NSE group continues its } \\
\text { existence between projects. }\end{array}$ \\
Porcini (2009) & $\begin{array}{l}\text { Before the most recent project "Lily } \\
\text { of the Valley," the group remains } \\
\text { dormant for a couple of years. One } \\
\text { of the members (albval) is totally } \\
\text { inactive in Wikipedia, but he is } \\
\text { invited to collaborate on a project. }\end{array}$
\end{tabular}

Lily of the Valley

(2013-2014)
Latency During Group Activities

The NSE group first takes shape.

\begin{abstract}
"Porcini" is the fourth collaborative project for the group. Some of the members meet face-to-face during summer 2009. The closer communication and face-to-face meetings enable a dynamic division of labor.
\end{abstract}

The NSE group comes together after a long period of inactivity. This collaboration is at least the tenth Featured Article project. Shared understanding of members' capabilities has developed to a high level. Specific knowledge needs (such as chemistry) are identified and supported from the group during collaboration.

(after)

The group continues as inactive.

It may spring up again for a new project in the future.

inactivity for someone who has learned the norms and the processes of a community. The concept of user-level latency builds on an established literature on lurking (Malinen 2015; Sun et al. 2014). Lurking has traditionally been viewed as passive engagement (Okoli et al. 2014). Only recently has passive lurking become distinguished from potent latency (Velasquez et al. 2014), the first stage in a gateway of deeper engagement (Lanamäki et al. 2015).

Our data show how the same group of contributors has collaborated time and time again, with periods of inactivity in between these active periods. These intense working periods are followed by periods of latency. A group may remain inactive for relatively long periods. Group latency does not necessarily mean that its individual members will remain inactive during the group's inactive period. Outside of the 
group, the member may work on other projects in other groups or with individual contributions. Outside of these reenacted projects, which have occurred a maximum of three times a year, the NSE team has remained in an inactive state.

The literature has expressed various similar ideas of group latency, such as in socalled seasonal organizations, like children's summer camps (Birnholtz et al. 2007). In such settings, the focus is on how routines are sustained over winter and reactivated in a similar fashion every summer. That research stream has established the ways in which organizations come "back to life" after long periods of latency, retaining their character as an entity and changing little. It is thus important to train and guide new people into their roles that serve them better than routines in nonrecurring situations (Birnholtz et al. 2007).

Though the groups in seasonal organizations regenerate at certain intervals (annually), there are also groups in which this expectation is not so clear. Even the remote anticipation of future interaction provides continuity (Bakker 2010). These streams of literature stress that latency and processes of reactivation require specific attention. Regardless of some similarities, seasonal organizations differ in two critical ways from latent groups. First of all, they reactivate within standard, expected intervals (for example, a summer camp is organized every summer). On Wikipedia, no such preset "season" exists. The only logic is the temporal logic of practice (Orlikowski and Yates 2002): a new Featured Article project occurs when suitable content and suitable contributors align. Second, seasonal organizations are mostly based on an explicitly defined, hierarchical managerial structure. Our latent group does not have a leader, though certain users do take leadership positions in situ within their collaborations.

Another related area of literature is dormancy. This concept has an extensive history in biology (e.g., Samish 1954). For example, bacteria "exist in metabolically inactive states that allow them to survive conditions that are not conducive for growth" and after a period of dormancy "may sense when conditions have improved and re-initiate growth" (Dworkin and Shah 2010).

When latency is seen as inactivity, we can find parallels between latent users (Velasquez et al. 2014) and latent groups. However, also during the active period, there are characteristics of the group that are visible or obvious to involved members but not to outsiders. We elaborate on this in the next section.

\subsection{Latency during group activities}

As we have previously argued, latency is often viewed as inactivity. But the dictionary definition states that latency is something that is "present and capable of emerging or developing but not now visible, obvious, active, or symptomatic." We argue that a latent group has latent characteristics also during the active period.

Even though the NSE has worked on many projects over the course of many years, it is very difficult for an outsider to identify the group in Wikipedia. There is no dedicated page for the group. Outsiders cannot identify the group from any label. 
Even the name "Natural Science Enthusiasts" was given to the group by us. The group members identified each other in interviews, but none of them called the group by any consistent name. This shows that the group is latent even when it is active.

The foundational Whooper Swan project involved explicit coordination that began on a discussion forum, then took place at the article talk page, then moved to the peer review page, and finally ended up on the FA nomination page. The NSE group formed dynamically through interactions between individual Wikipedia contributors. In other words, the collaboration facilitates an emergent state of the group to take place for the first time. NSE represents a handful of participants who share an interest in natural sciences in general and biology in particular. The starting point was that members have contributed to individual articles. Later on, the same people have joined together time and time again.

Extant research has shown how Wikipedia activities include various types of group work. Latent groups provide a new lens into this literature. Previously, Wikipedia and other open collaboration platforms have been found to support governance through "persistent but malleable social structures" (Forte and Lampe 2013). Additionally, coordinated project work takes place on dedicated project pages such as Wikiprojects (Morgan et al. 2014; Morgan et al. 2013). In summary, Wikipedia group work literature has discussed various types of manifest groups that are explicitly identifiable on the platform to enable collaborative work.

It is worth reflecting on the kinds of settings in which latent groups are more feasible than manifest groups. One aspect is that manifest groups are based on a priori self-declaration in the group - but that does not yet imply commitment at the point when it is needed. In contrast, latent group members are committing without a selfdeclaration. The logic of an FA project as a limited-time process supports the organization as a latent group.

While in this article we have contrasted between latent and manifest groups, we acknowledge that the difference is clear only when talking about ideal types (Weber 1949). A group that was born latent may later manifest itself on a Wikipedia project page.

Organizing as a latent group might be a phenomenon encountered mostly in sparse-resource communities such as the Finnish Wikipedia we studied. The number of Finnish-language Wikipedia contributors is relatively small. The number of those interested in natural science topics is even smaller. This is a central reason why this kind of group work has remained sustained over time. It is simply unlikely that another natural science expert would find her or his way to the right article at the right time only by chance. The small pool of interested, capable, and available contributors is one of the reasons such coordinated group work as the NSE projects has taken place. They have found their individual capabilities to complement each other, and thus their collaboration has provided effective results. 


\section{Implications and limitations}

\subsection{Implications for research}

The central contribution of this article is the theorizing of latent group as a lens to view group work in online communities. We acknowledge the similarities between our theoretical contribution and earlier conceptualizations related to "the small-world phenomenon" (Uzzi and Spiro 2005; Milgram 1967). Latent groups are also dependent on interpersonal relationships as a central resource to creativity and collaboration. Yet, we emphasize several differences, pointing out that latent groups are not an instance of the small-world phenomenon. For example, the argument Uzzi and Spiro (2005) make is based on a study of Broadway musicals. That kind of professional face-to-face social situation is inherently different from the pseudonymous voluntary-based online setting of Wikipedia.

Second, Uzzi and Spiro discuss how the social network is the source of creativity and collaboration. In their data, the group that performs each musical project is different. In contrast, our latent group is by and large the same across the different projects, even over periods of dormancy.

Our paper contributes to an improved understanding of latency not just as a characteristic of a user (Velasquez et al. 2014), but as a group-level concept. It also furthers our understanding of group work in online communities, beyond manifest groups such as Wikiprojects (Morgan et al. 2014; Morgan et al. 2013).

The membership turnover literature (Ransbotham and Kane 2011; Aaltonen and Kallinikos 2013) has discussed how contributors leave soon after they have joined. Research attempts have been made to prolong positive engagement in Wikipedia (Halfaker et al. 2014; Arazy et al. 2013). In our research, the eight years of mutual group collaboration contrasts these depictions. Building an environment that fosters these kinds of groups may hold a key to how to extend engagements.

We also provide a set of methodological contributions. The contributions are set toward tendencies in online community research. We complement approaches that have taken individual users or individual articles as a unit of analysis. Our approach is sensitive to collaborative practices distributed across time and space. Combining trace ethnography and in-depth interviews has provided this advantage. In-depth interviews have helped open the door "behind the scenes"-identifying group members, applied artifacts, and coordinated activities at different phases of collaboration. These methods have helped us to go study what may have been difficult to observe by using "edit counts," for example.

Therefore, complementing interviews with trace ethnography can help in identifying shared practices that are distributed and easy to miss. The number of edits does not necessarily show which users are working together on the same article or the amount of work they put in. This is because edits only show which user pressed the save button on the edit rather than the process that led to that point, while some users in Wikipedia collaboration work on the links from a particular article rather than the article itself. This also hints that the production of one high-quality article 
necessitates the creation of a number of other, related articles. In addition, some tasks such as language improvement may involve relatively more work, but may seem to be a minor contribution in an edit-based analysis. Work also takes place when authors discuss issues outside Wikipedia (as in emails or even meetings).

Additionally, the literature has noted that studying inactive users is difficult, since their activities do not leave traces. Our idea of latent groups helps us comprehend one type of inactivity that has been underreported in previous research literature. This may clarify the activities of topic experts in Wikipedia and how they go through active and passive periods.

\subsection{Implications for practice}

Our findings have several practical implications for different audiences interested in different types of group work. Extant research has provided various tools to support contributions and collaboration in Wikipedia. These include newcomer engagement tools such as SuggestBot (Cosley et al. 2007), Snuggle (Halfaker et al. 2014), and LeadWise (Flores-Saviaga et al. 2016). These kinds of collaboration filtering tools have helped identify contributors who have similar interests. Our research provides a theoretical lens to understand collaborative captured by such tools. As the collaborations we studied were supported by such tools, it shows that even Wikipedia's default features allow group work that persists over several years and through various Featured Article projects. Even though Wikipedia is oriented toward individual sporadic contributions, the platform can be appropriated for sustaining collaborative group work. As the old idiom states, when there's a will, there's a way.

Our contributions add to the portfolio of the kinds of social dynamics involved in Wikipedia collaboration. While the NSE group members in our research are making use of Wikipedia's default features, it is still worthwhile to ponder whether latent groups could benefit from additional tools. Many of the tools that currently support editing and report edits seem to start with the assumption of a sporadic, ad hoc, and individual work. There is nothing wrong with this, but there appears to be a need to support a wider variety of collaborations. For example, Wikiprojects (Morgan et al. 2014; Morgan et al. 2013) represent an interesting approach in this regard. However, Wikiprojects are manifest groups. Wikiprojects may work better in settings that involve a large pool of potential contributors, as seen in English Wikipedia (e.g., Ozturk and Nickerson 2015). In the case of Finnish Wikipedia, the pool is very limited.

Latent group activities originate from enthusiastic individuals collaborating on projects. Often, the beginning for such collaboration might be accidental. Further research might investigate whether such coming-together of latent group work could be better supported with technological tools. For example, could there be more "social" messaging in Wikipedia in addition to technical discussions on Wikipedia article contents?

It might be of great benefit if latent group work could be better identified using analytic tools. Such tools might extract data from a multitude of articles over time 
and identify which users have co-authored many projects. Experiences with the SuggestBot (Cosley et al. 2007) - a newcomer engagement tool - may be beneficially transferred into this context. This might give these groups a more visible presence in Wikipedia. Currently, the tracking of activities starts with individual users, articles, and edits, but this could be complemented by group-level functions. Enabling belonging to a group might then also allow following in detail which projects attract certain groups of experts. These kinds of tools might be useful outside Wikipedia.

We also complement the design opportunities identified by Velasquez et al. (2014) in their latent users study. They pointed out that the "existence of latent users ... imposes a new challenge to designers and administrators as to how to identify and attract latent users to contribute again to these sites" (p. 46). This is true for latent groups as well. In contrast to latent users, latent groups can act in a greater capacity when put in action.

\subsection{Limitations and further avenues for research}

In this section, we discuss the limitations of this study. As this is a qualitative study of one group in Finnish Wikipedia, terms and conditions apply. What can one quite small group in a peripheral part of Wikipedia tell us about online communities? What does it tell about all the other groups in different versions of Wikipedia? In response to this concern, we would like to answer that the policies, procedures (for example the FA-process), and technical tools of the platform are rather similar across different language editions (Jones 2008; Kane et al. 2014; Stein and Hess 2007). Many Wikipedians also talk in and edit several Wikipedia language versions. Thus, although we welcome comparative studies across the different language versions of Wikipedia, we do posit that what holds true for Finnish Wikipedia might also be relevant for other language versions. Finland may also offer some unique characteristics. For example, Finland, as the home country of Linus Torvalds (the developer of Linux operating system), has a long tradition of voluntary-based virtual group work. Another characteristic is that Wikipedia is the only encyclopedia still maintained in Finnish. A small language context also mean that the contributing populations might be considerably smaller than in some other language editions, which might moderate our findings related to the number of groups and their periods of latency.

Additionally, while we have studied group work, we do not think too sharp a contrast between groups and sporadic individual contributions is fruitful. Individual contributions may happen despite the group being latent or active. Groups may be latent for a relatively long time, during which individual members may work on their other projects.

This research raises a number of research questions that could be pursued further. The first group of questions concerns identifying groups. Who are the members? Are 
there automated tools that could be used to track them? Especially interesting would be to identify those groups that are currently latent but might become active.

We have conceptualized latent groups in this paper. As this is the first time this concept has been introduced, the characterization of this phenomenon is necessarily impartial. Latent groups may be a very common organizational form through which work comes together in open collaboration contexts like Wikipedia. Focusing research only on manifest groups, or only on active participation, will result in an incomplete picture of group dynamics.

Our research raises several interesting questions regarding the project-based organization literature (Huemann et al. 2007; Keegan and Rodney Turner 2002) and how virtual, volunteer-based organizations such as Wikipedia reshape our understanding of how those project-based groups work. Thus far, project-based organization literature has addressed voluntary work, but mostly only in traditional offline settings (Miterev et al. 2017).

Future research should further investigate the dynamics of latent groups in various settings. For example, the mechanisms of group reactivation might be worth studying. Dormancy implies periods of inactivity after which the group becomes active again. Therefore, it would be imperative to study further how reactivation works. Additionally, another logical point for further research is to examine contexts other than Wikipedia. Latent groups may be important for other open, virtual, collaborative environments.

The last theme of future research opportunities concerns the "management" and governance of these groups. Contributions in Wikipedia and in many other similar platforms are based on voluntary task assignment. This means there are limits to what different stakeholders in organizations can do to attract certain kinds of contributions. Targeting specific groups of enthusiasts or topic experts rather than the entire population of sporadically contributing individuals may hold promise.

\section{Acknowledgements}

This paper has been under development since 2013, and is partially based on data collected during the first author's doctoral thesis work (Lanamäki 2013). We would like to thank all researchers who have guided and supported the development of this paper in any way during these years. Karin Väyrynen, Netta Iivari, Kari Kuutti, Tonja Molin-Juustila, Marianne Kinnula, and Mike Chiasson have all provided useful comments to earlier drafts. We would also like to thank participants of University of Gothenburg Informatics Higher seminar and Stanford Scandinavian Consortium for Organizational Research Friday seminar for their feedback on the earlier versions of this work. The paper found its final form during 2016-2017 while under review in JCSCW. We give our greatest thanks to the associate editor Luigina Ciolfi and the two anonymous reviewers, for facilitating a developmentoriented peer review process. 


\section{Appendix}

Table 4. Data sources and analyses.

\begin{tabular}{|c|c|c|}
\hline Data source & Description & Data analysis technique \\
\hline $\begin{array}{l}\text { Initial face-to-face } \\
\text { interviews }\end{array}$ & $\begin{array}{l}13 \text { individual interviews with } \\
\text { active Finnish Wikipedia } \\
\text { contributors were conducted } \\
\text { face-to-face in January } 2010\end{array}$ & $\begin{array}{l}\text { Four respondents self-identified } \\
\text { themselves as members of NSE } \\
\text { (Natural Science Enthusiasts). } \\
\text { The initial interviews provided many } \\
\text { clues of Wikipedia articles that should } \\
\text { be further analyzed. }\end{array}$ \\
\hline Article content & $\begin{array}{l}\text { We chose three articles from the } \\
\text { evolution of the group: The } \\
\text { foundational project "Whooper } \\
\text { Swan" (2007), the most recent } \\
\text { project "Lily of the Valley" } \\
\text { (2013-14), and one project from } \\
\text { between, "Porcini" (2009) }\end{array}$ & $\begin{array}{l}\text { The histories of these three articles } \\
\text { were thoroughly examined. }\end{array}$ \\
\hline Article edit histories & $\begin{array}{l}\text { The wiki platform has archived } \\
\text { edit histories of each article. }\end{array}$ & $\begin{array}{l}\text { Analyzing the edit history reveals } \\
\text { what has been developed during the } \\
\text { tenure of the article and when, as } \\
\text { well as who did the editing. }\end{array}$ \\
\hline Talk pages & $\begin{array}{l}\text { The three articles we had chosen } \\
\text { had talk pages where the } \\
\text { discussion about the article } \\
\text { was held }\end{array}$ & $\begin{array}{l}\text { Much of the discussions related to } \\
\text { article development (such as errors, } \\
\text { conflicts, gap-spotting) are held on } \\
\text { the article talk pages. }\end{array}$ \\
\hline User talk pages & $\begin{array}{l}\text { Some of the article collaborations } \\
\text { originated in discussions between } \\
\text { users on user talk pages. }\end{array}$ & $\begin{array}{l}\text { Hyperlinks on other pages and search } \\
\text { engines were applied in identifying } \\
\text { discussions about the article project. }\end{array}$ \\
\hline $\begin{array}{l}\text { Wikipedia discussion } \\
\text { forums, also known } \\
\text { as the "community } \\
\text { pump" }\end{array}$ & $\begin{array}{l}\text { Some article collaborations } \\
\text { originated from general } \\
\text { discussions } \\
\text { held on the Wikipedia forums. }\end{array}$ & $\begin{array}{l}\text { Hyperlinks on other pages and search } \\
\text { engines were applied in identifying } \\
\text { discussions about the article project. }\end{array}$ \\
\hline $\begin{array}{l}\text { Good and Featured } \\
\text { Article project pages }\end{array}$ & $\begin{array}{l}\text { All of the three examined article } \\
\text { projects had eventually resulted in } \\
\text { the Featured Article (FA) status. } \\
\text { We analyzed the FA project pages, } \\
\text { and the preceding Good Article } \\
\text { (GA) pages when applicable. }\end{array}$ & $\begin{array}{l}\text { We identified who were active during } \\
\text { the GA and FA processes, in which } \\
\text { activities, and how the process } \\
\text { evolved. }\end{array}$ \\
\hline Wikipedia tools & $\begin{array}{l}\text { We applied several tools that } \\
\text { helped us trace, quantify, and } \\
\text { visualize the content in Wikipedia. } \\
\text { An extensive list of tools is } \\
\text { available on https://en.wikipedia. } \\
\text { org/wiki/Wikipedia:Tools }\end{array}$ & $\begin{array}{l}\text { The tools helped us identify periods } \\
\text { of inactivity and activity in the tenure } \\
\text { of the article. We also could analyze } \\
\text { the division of labor and the amount } \\
\text { of tasks each contributor has } \\
\text { provided. }\end{array}$ \\
\hline
\end{tabular}


Table 4. (continued)

\begin{tabular}{|c|c|c|}
\hline Data source & Description & Data analysis technique \\
\hline $\begin{array}{l}\text { Subsequent interview } \\
\text { with two respondents } \\
\text { at once }\end{array}$ & $\begin{array}{l}\text { Two of the original interviewees } \\
\text { were interviewed again in } \\
\text { February } 2014 .\end{array}$ & $\begin{array}{l}\text { Our purpose was to get updates of the } \\
\text { group activities between } 2010 \text { and } \\
2014 \text {. We also fed back our } \\
\text { interpretations and theorizations to our } \\
\text { respondents to provide validation. }\end{array}$ \\
\hline $\begin{array}{l}\text { Email } \\
\text { correspondence }\end{array}$ & $\begin{array}{l}\text { Emails were sent back and forth } \\
\text { between informants during } 2014 \text {. }\end{array}$ & $\begin{array}{l}\text { We asked for clarifications directly on } \\
\text { the emergence group and other } \\
\text { unclear issues about the key persons. }\end{array}$ \\
\hline
\end{tabular}

\section{References}

Aaltonen, Aleksi; and Jannis Kallinikos (2013). Coordination and Learning in Wikipedia: Revisiting the Dynamics of Exploitation and Exploration. In M. Holmqvist; and A. Spicer (eds), Managing 'Human Resources' by Exploiting and Exploring People's Potentials (Research in the Sociology of Organizations, Volume 37): Emerald Group Publishing Limited, pp. 161-192.

Adler, Paul S.; and Seok-Woo Kwon (2002). Social capital: Prospects for a new concept. Academy of Management Review, vol. 27, no. 1, pp. 17-40.

Antin, Judd; and Coye Cheshire (2010). Readers are Not Free-Riders: Reading as a Form of Participation on Wikipedia. In CSCW 2010. Proceedings of the ACM Conference on Computer Supported Cooperative Work. Savannah, Georgia, USA, 6-10 February 2010. New York: ACM, pp. 127-130.

Arazy, Ofer; Hila Lifshitz-Assaf; Oded Nov; Johannes Daxenberger; Martina Balestra; and Coye Cheshire (2017). On the "How" and "Why" of Emergent Role Behaviors in Wikipedia. In CSCW 2017. Proceedings of the ACM conference on computer-supported cooperative work and social Computing, Portland, Oregon, USA, 25 February - 01 March 2017. New York: ACM, pp. 2039-2051.

Arazy, Ofer; Felipe Ortega; Oded Nov; Lisa Yeo; and Adam Balila (2015). Functional Roles and Career Paths in Wikipedia. In CSCW 2015. Proceedings of the ACM conference on computer supported cooperative work and social Computing, Vancouver, BC, Canada, 14-18 March 2015. New York: ACM, pp. 1092-1105.

Arazy, Ofer; Lisa Yeo; and Oded Nov (2013). Stay on the Wikipedia task: When task-related disagreements slip into personal and procedural conflicts. Journal of the American Society for Information Science \& Technology, vol. 64, no. 8, pp. 1634-1648.

Bakker, René M. (2010). Taking stock of temporary organizational forms: A systematic review and research agenda. International Journal of Management Reviews, vol. 12, no. 4, pp. 466-486.

Bannon, Liam J.; and Kjeld Schmidt (1989). CSCW: Four Characters in Search of a Context. In European Conference on Computer Supported Cooperative Work, 13-15 September 1989, Gatwick, London. London: Computer Sciences Company, pp. 358-372. https://dl.eusset.eu/ dspace/handle/20.500.12015/1870

Benkler, Yochai (2007). The wealth of networks : How social production transforms markets and freedom. New Haven and London: Yale University Press.

Birnholtz, Jeremy P.; Michael D. Cohen; and Susannah V. Hoch (2007). Organizational character: On the regeneration of camp poplar grove. Organization Science, vol. 18, no. 2, pp. 315-332.

Black, Laura W.; Howard T. Welser; Dan Cosley; and Jocelyn M. DeGroot (2011). Self-governance through group discussion in Wikipedia: Measuring deliberation in online groups. Small Group Research, vol. 42, no. 5, pp. 595-634. 
Broughton, John (2008). Wikipedia: The missing manual. Sebastopol, CA, USA: O'Reilly Media.

Bygstad, Bendik; and Bjørn Erik Munkvold (2011). Exploring the role of informants in interpretive case study research in IS. Journal of Information Technology, vol. 26, pp. 32-45.

Cosley, Dan; Dan Frankowski; Loren Terveen; and John Riedl (2007). SuggestBot: Using intelligent task routing to help people find work in Wikipedia. In IUI '07. Proceedings of the 12th International Conference on Intelligent User Interfaces. Honolulu, Hawaii, USA. 28-31 January 2007. New York: ACM, pp. 32-41.

Cranefield, Jocelyn; Pak Yoong; and Sid L. Huff (2015). Rethinking lurking: Invisible leading and following in a knowledge transfer ecosystem. Journal of the Association for Information Systems, vol. 16, no. 4, pp. 213-247.

Curşeu, Petru Lucian; and Sandra G. L. Schruijer (2010). Does conflict shatter trust or does trust obliterate conflict? Revisiting the relationships between team diversity, conflict, and trust. Group Dynamics: Theory, Research, Practice, vol. 14, no. 1, pp. 66-79.

Czarniawska, Barbara (2017). Actor-network theory. In A. Langley; and H. Tsoukas (eds), The SAGE handbook of process organization studies. London: SAGE, pp. 160-173.

Daraghmi, Eman Yasser; and Shyan-Ming Yuan (2014). We are so close, less than 4 degrees separating you and me! Computers in Human Behavior, vol. 30, pp. 273-285.

Dejean, Sylvain; and Nicolas Jullien (2015). Big from the beginning: Assessing online contributors' behavior by their first contribution. Research Policy, vol. 44, no. 6, pp. 1226-1239.

Dennen, Vanessa Paz (2008). Pedagogical lurking: Student engagement in non-posting discussion behavior. Computers in Human Behavior, vol. 24, no. 4, pp. 1624-1633.

Dworkin, Jonathan; and Ishita M. Shah (2010). Exit from dormancy in microbial organisms. Nature Reviews Microbiology, vol. 8, no. 12, pp. 890-896.

Flores-Saviaga, Claudia; Saiph Savage; and Dario Taraborelli (2016). LeadWise: Using Online Bots to Recruite and Guide Expert Volunteers. In CSCW 2016. Proceedings of the ACM Conference on Computer Supported Cooperative Work and Social Computing Companion. San Francisco, California, USA, 26 February - 2 March 2016. New York: ACM, pp. 257-260.

Forte, Andrea; and Cliff Lampe (2013). Defining, understanding, and supporting open collaboration: Lessons from the literature. American Behavioral Scientist, vol. 57, no. 5, pp. 535-547.

Geiger, R. Stuart; and David Ribes (2011). Trace ethnography: Following coordination through documentary practices. In HICSS 2011. Proceedings of the 44th Hawaii International Conference on System Sciences. Kauai, HI, USA. 4-7 January 2011. IEEE computer Society, pp. 1-10.

Grannis, Rick (2010). Six degrees of "who cares?”. American Journal Of Sociology, vol. 115, no. 4, pp. 991-1017.

Halfaker, Aaron; R. Stuart Geiger; Jonathan T. Morgan; and John Riedl (2013a). The rise and decline of an open collaboration system: How Wikipedia's reaction to popularity is causing its decline. American Behavioral Scientist, vol. 57, no. 5, pp. 664-688.

Halfaker, Aaron; R. Stuart Geiger; and Loren G. Terveen (2014). Snuggle: designing for efficient socialization and ideological critique. In CHI 2014. Proceedings of the SIGCHI Conference on Human Factors in Computing Systems. Toronto, Ontario, Canada, 26 April - 1 May 2014. New York: ACM, pp. 311-320.

Halfaker, Aaron; Oliver Keyes; and Dario Taraborelli (2013b). Making peripheral participation legitimate: reader engagement experiments in Wikipedia. In CSCW 2013. Proceedings of the ACM Conference on Computer Supported Cooperative Work. San Antonio, Texas, USA, 23-27 February 2013. New York: ACM, pp. 849-860.

Hansen, Sean; Nicholas Berente; and Kalle Lyytinen (2009). Wikipedia, critical social theory, and the possibility of rational discourse. Information Society, vol. 25, no. 1, pp. 38-59.

Himelboim, Itai; Marc A. Smith; Lee Rainie; Ben Shneiderman; and Camila Espina (2017). Classifying twitter topic-networks using social network analysis. Social Media + Society, vol. 3, no. 1 , pp. 1-13. 
Huemann, Martina; Anne Keegan; and J. Rodney Turner (2007). Human resource management in the project-oriented company: A review. International Journal of Project Management, vol. 25, no. 3, pp. 315-323.

Jarzabkowski, Paula (2004). Strategy as practice: Recursiveness, adaptation, and practices-in-use. Organization Studies, vol. 25, no. 4, pp. 529-560.

Jemielniak, Dariusz (2014). Common knowledge? An ethnography of Wikipedia. Stanford: Stanford University Press.

Jiang, Ling; and Christian Wagner (2015). Perceptions of justice or injustice as determinants of contributor defections from online communities. Journal of the Association for Information Science and Technology, vol. 66, no. 7, pp. 1477-1493.

Jones, John (2008). Patterns of revision in online writing : A study of Wikipedia's featured articles. Written Communication, vol. 25, no. 2, pp. 262-289.

Kane, Gerald C.; Jeremiah Johnson; and Ann Majchrzak (2014). Emergent life cycle: The tension between knowledge change and knowledge retention in open online coproduction communities. Management Science, vol. 60, no. 12, pp. 3026-3048

Kane, Gerald C.; and Sam Ransbotham (2016). Content as community regulator: The recursive relationship between consumption and contribution in open collaboration communities. Organization Science, vol. 27, no. 5, pp. 1258-1274.

Keegan, Anne; and J. Rodney Turner (2002). The Management of Innovation in project-based firms. Long Range Planning, vol. 35, no. 4, pp. 367-388.

Keegan, Brian C. (2015). Emergent Social Roles in Wikipedia's Breaking News Collaborations. In E. Bertino; and S. A. Matei (eds), Roles, Trust, and Reputation in Social Media Knowledge Markets (Computational Social Sciences): Springer International Publishing, pp. 57-79.

Keegan, Brian; Darren Gergle; and Noshir Contractor (2012). Do editors or articles drive collaboration?: multilevel statistical network analysis of wikipedia coauthorship. In CSCW 2012. Proceedings of the ACM Conference on Computer Supported Cooperative Work. Seattle, Washington, USA, 11-15 February 2012. New York: ACM, pp. 427-436.

Kudaravalli, Srinivas; and Samer Faraj (2008). The structure of collaboration in electronic networks. Journal of the Association for Information Systems, vol. 9, no. 10/11, pp. 706-726.

Kuutti, Kari; and Liam Bannon (2014). The turn to practice in HCI: towards a research agenda. In CHI 2014. Proceedings of the SIGCHI Conference on Human Factors in Computing Systems. Toronto, Ontario, Canada, 26 April - 1 May 2014. New York: ACM, pp. 3543-3552.

Lanamäki, Arto (2013). Collaboration in online communities: Exploring Finnish Wikipedia. Thesis, University of Bergen, Bergen, Norway.

Lanamäki, Arto; Mikko Rajanen; Anssi Öörni; and Netta livari (2015). Once you step over the first line, you become sensitized to the next: Towards a gateway theory of online participation. In ICIS 2015. Thirty Sixth International Conference on Information Systems, Fort Worth, Texas, USA, 1316 December 2015. AIS, pp. 1-17.

Liao, Han-Teng (2009). Conflict and consensus in the Chinese version of Wikipedia. IEEE Technology \& Society Magazine, vol. 28, no. 2, pp. 49-56.

Locke, Karen (2011). Field research practice in management and organization studies: Reclaiming its tradition of discovery. The Academy of Management Annals, vol. 5, no. 1, pp. 613-652.

Malinen, Sanna (2015). Understanding user participation in online communities: A systematic literature review of empirical studies. Computers in Human Behavior, vol. 46, pp. 228238.

Martela, Frank (2015). Fallible inquiry with ethical ends-in-view: A pragmatist philosophy of science for organizational research. Organization Studies, vol. 36, no. 4, pp. 537-563.

Mathieu, John E.; Tonia S. Heffner; Gerald F. Goodwin; Janis A. Cannon-Bowers; and Eduardo Salas (2005). Scaling the quality of teammates' mental models: Equifinality and normative comparisons. Journal of Organizational Behavior, vol. 26, no. 1, pp. 37-56. 
Mesgari, Mostafa; Chitu Okoli; Mohamad Mehdi; Finn Årup Nielsen; and Arto Lanamäki (2015). "the sum of all human knowledge": A systematic review of scholarly research on the content of Wikipedia. Journal of the Association for Information Science and Technology, vol. 66, no. 2, pp. 219-245.

Milgram, Stanley (1967). The small-world problem. Psychology Today, vol. 1, no. 1, pp. 62-67.

Miterev, Maxim; Mauro Mancini; and Rodney Turner (2017). Towards a design for the project-based organization. International Journal of Project Management, vol. 35, no. 3, pp. 479-491.

Morgan, Jonathan T.; Michael Gilbert; David W. McDonald; and Mark Zachry (2014). Editing Beyond Articles: Diversity \& Dynamics of Teamwork in Open Collaborations. In CSCW 2014. Proceedings of the ACM Conference on Computer Supported Cooperative Work and Social Computing. Baltimore, Maryland, USA, 15-19 February 2014. New York: ACM, pp. 550-563.

Morgan, Jonathan T.; Michael Gilbert; Mark Zachry; and David McDonald (2013). A Content Analysis of WikiProject Discussions: Toward a Typology of Coordination Language Used by Virtual Teams. In CSCW 2013. Proceedings of the ACM Conference on Computer Supported Cooperative Work. San Antonio, Texas, USA, 23-27 February 2013. New York: ACM, pp. 231234.

Myers, Michael D. (2013). Qualitative research in Business \& Management (2nd ed.). London: Sage Publications Ltd.

Nemoto, Keiichi; Peter Gloor; and Robert Laubacher (2011). Social capital increases efficiency of collaboration among Wikipedia editors. In $H T^{\prime} 11$. Proceedings of the 22nd ACM conference on Hypertext and Hypermedia. Eindhoven, The Netherlands, 6-9 June 2011. New York: ACM, pp. 231-240.

Nicolini, Davide (2013). Practice theory, work, \& organization: An introduction. Oxford: Oxford University Press.

Nielsen, Jakob (2006). Participation Inequality: Encouraging More Users to Contribute. https:// www.nngroup.com/articles/participation-inequality/

Okhuysen, Gerardo A.; and Hettie A. Richardson (2007). Group conflict as an emergent state: Temporal issues. In K. J. Behfar; and L. L. Thompson (eds), Conflict in organizational groups: New directions in theory and practice. Evanston, IL: Northwestern University Press, pp. 145-180.

Okoli, Chitu; Mohamad Mehdi; Mostafa Mesgari; Finn Årup Nielsen; and Arto Lanamäki (2014). Wikipedia in the eyes of its beholders: A systematic review of scholarly research on Wikipedia readers and readership. Journal of the Association for Information Science and Technology, vol. 65, no. 12 , pp. 2381-2403.

Okoli, Chitu; and Wonseok Oh (2007). Investigating recognition-based performance in an open content community: A social capital perspective. Information \& Management, vol. 44, no. 3, pp. 240-252.

Orlikowski, Wanda J.; and JoAnne Yates (2002). It's about time: Temporal structuring in organizations. Organization Science, vol. 13, no. 6, pp. 684-700.

Ozturk, Pinar; and Jeffrey V. Nickerson (2015). Paths from talk to action. In ICIS 2015. Thirty Sixth International Conference on Information Systems, Fort Worth, Texas, USA, 13-16 December 2015. AIS, pp. 1-18.

Preece, Jennifer; and Ben Shneiderman (2009). The reader-to-leader framework: Motivating Technology-mediated social participation. AIS Transactions on Human-Computer Interaction, vol. 1, no. 1, pp. 13-32.

Priedhorsky, Reid; Jilin Chen; Shyong K. Lam; Katherine Panciera; Loren Terveen; and John Riedl (2007). Creating, destroying, and restoring value in Wikipedia. In GROUP'07. Proceedings of the International ACM Conference on Supporting Group Work. Sanibel Island, Florida, USA, 4-7 November 2007. New York: ACM, pp. 259-268.

Rafaeli, Sheizaf; Gilad Ravid; and Vladimir Soroka (2004). De-lurking in virtual communities: A social communication network approach to measuring the effects of social and cultural capital. In 
HICSS 2004. Proceedings of the 37th Hawaii International Conference on System Sciences. Big Island, HI, USA. 5-8 January 2004. IEEE, pp. 1-10.

Ransbotham, Sam; and Gerald C. Kane (2011). Membership turnover and collaboration success in online communities: Explaining rises and falls from grace in Wikipedia. MIS Quarterly, vol. 35, no. 3, pp. 613-627.

Reagle, Joseph M. (2010). Good Faith Collaboration (history and foundations of information science). Cambridge, Massachusetts: The MIT Press.

Samish, R.M. (1954). Dormancy in Woody plants. Annual Review of Plant Physiology, vol. 5, no. 1, pp. 183-204.

Smith, Marc A.; and Peter Kollock (1999). Communities in cyberspace. London: Routledge.

Solomon, Jacob; and Rick Wash (2014). Critical Mass of What? Exploring Community Growth in WikiProjects. In ICWSM'14. Proceedings of the Eighth International AAAI Conference on Weblogs and Social Media. Ann Arbor, Michigan, USA, 1-4 June 2014: AAAI Press, pp. 476-484.

Stein, Klaus; and Claudia Hess (2007). Does It Matter Who Contributes? - A Study on Featured Articles in the German Wikipedia. In HT'07. Proceedings of the Eighteenth Conference on Hypertext and Hypermedia. Manchester, UK. 10-12 September 2007. New York: ACM, pp. 171-174.

Stvilia, Besiki; Abdullah Al-Faraj; and Yong Jeong Yi (2009). Issues of cross-contextual information quality evaluation-The case of Arabic, English, and Korean Wikipedias. Library \& Information Science Research, vol. 31, no. 4, pp. 232-239.

Sun, Na; Patrick Pei-Luen Rau; and Liang Ma (2014). Understanding lurkers in online communities: A literature review. Computers in Human Behavior, vol. 38, pp. 110-117.

Uzzi, Brian; and Jarrett Spiro (2005). Collaboration and creativity: The small world problem. American Journal Of Sociology, vol. 111, no. 2, pp. 447-504.

Waller, Mary J.; Gerardo A. Okhuysen; and Marzieh Saghafian (2016). Conceptualizing emergent states: A strategy to advance the study of group dynamics. The Academy of Management Annals, vol. 10, pp. 561-598.

Weber, Max (1949). The Methodology of the Social Sciences (E. A. Shils; and H. A. Finch, trans., First ed.). Glencoe, IL: Free Press.

Velasquez, Alcides; Rick Wash; Cliff Lampe; and Tor Bjornrud (2014). Latent users in an online usergenerated content community. Computer Supported Cooperative Work (CSCW), vol. 23, no. 1, pp. 21-50.

Wellman, Barry; and Lee Rainie (2012). Networked: The new social operating system. Cambridge, Massachusetts: The MIT Press.

Zammuto, Raymond F.; Terri L. Griffith; Ann Majchrzak; Deborah J. Dougherty; and Samer Faraj (2007). Information Technology and the changing fabric of organization. Organization Science, vol. 18 , no. 5 , pp. $749-762$. 